Filol. linguist. port., n. 13(2), p. 459-476, 2011

\title{
Vestígios da memória e da escrita colonial brasileira em uma carta oficial do século XVIII
}

\author{
Traces of memory and writing from the Brazilian \\ colonial period in an official letter written in the \\ eighteenth Century
}

\author{
Vanessa Regina Duarte Xavier ${ }^{1}$
}

\begin{abstract}
RESUMO: Este artigo compõe-se da análise de uma carta oficial do século XVIII, com base nas lexias que revelam aspectos sócio-culturais da Capitania goiana no período colonial, referendados por Salles (1992). A edição semidiplomática da carta baseou-se nos critérios disponíveis em Megale e Toledo Neto (2005) e visou à composição de uma fonte confiável às investigações de ordem linguística. Fizemos, ainda, apontamentos sobre a carta oficial e a influência da hierarquia social da época na estruturação do discurso (Berlinck; Barbosa; Marine, 2008). E, por fim, levantamos algumas variantes grafemáticas presentes no texto, com vistas a demonstrar que também os documentos oficiais se prestam aos estudos temáticos da variação linguística, pois a grafia encontrada recebe influência da oralidade (Mattos e Silva, 2008).
\end{abstract}

Palavras-chave: Filologia; História; Memória; Variação Grafemática.

\begin{abstract}
This paper is an analysis of an official letter from the eighteenth century, detailing lexias showing the cultural aspects of the captaincy of Goiás in the colonial period of Brazil, upheld by Salles (1992). The semi-diplomatic edition of the letter was based on criteria available in Megale and Toledo Neto (2005) and its objective was to compose a reliable source of linguistic research. We also comment on the official letter and on how the social hierarchy of the period influenced the structure of discourse (Berlinck; Barbosa; Marine, 2008). And, finally, we highlight some graphematic variation in the text, indicating that official documents are also helpful in studies of linguistic variation, because the writing contained in them reveals the influence of orality (Mattos and Silva, 2008).
\end{abstract}

Keywords: Philology; History; Memory; Graphematic Variation.

1 Universidade de São Paulo, Doutoranda bolsista FAPESP. E-mail: vrdxavier@gmail.com 


\section{INTRODUÇÃO}

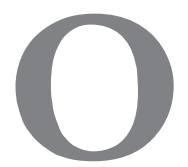

s documentos antigos preservam para as gerações futuras a memória de acontecimentos passados. Nesse sentido, são repositórios da história das mais diversas civilizações ao longo dos anos. Vale frisar o papel da escrita nesse processo de conservação da memória, uma vez que ela insurge como uma substância duradoura capaz de registrar eventos, e, por conseguinte, aspectos sócio-culturais que são de suma relevância para que a posteridade possa compreender como a sociedade se constituiu até atingir o seu estágio atual de desenvolvimento. À esteira de Acioli (1994: 18), a escrita "não é somente um meio de fixar a palavra, ou uma espécie de linguagem visual permanente; ela é a explicação do progresso do espírito humano, pois contribuiu para acumular e transmitir experiências que, antes de sua existência, se limitavam à tradição legendária".

Em virtude disso, não restam dúvidas de que é fundamental promover ações relacionadas à preservação desse patrimônio histórico-cultural, tanto se exigindo o manuseio adequado dos documentos antigos nas instituições responsáveis pela sua guarda, quanto mediante iniciativas como a digitalização do acervo e a sua edição conservadora.

No tangente aos documentos referidos, observa-se que eles são materiais valiosos aos estudos históricos da língua, ou seja, à análise da sua constituição e do seu funcionamento em tempos remotos, tendo em vista que a identidade da língua portuguesa em uso no Brasil nos dias atuais presta contas às mudanças por ela engendradas historicamente.

Isto posto, os documentos oficiais, em especial os de cunho diplomático, constituem fontes com grande potencial aos estudos históricos, haja vista que abarcam representações legítimas de fatos passados. Segundo Acioli (1994: 1), o documento "proporciona recursos inestimáveis ao historiador, representando o melhor testemunho do passado, fonte direta de informação básica para o estudo da História".

Nessa perspectiva, este estudo pretende resgatar aspectos sociais, históricos e culturais, a par dos elementos que configuraram a língua em uso na sociedade goiana em meados do século XVIII, tendo como ponto de partida a análise de um documento oficial desse período, escrito em Vila Boa de Goiás, atual Cidade de Goiás, cuja edição semidiplomática será aqui disponibilizada. 
Para tanto, destacaremos algumas lexias do documento, que revelam importantes propriedades acerca da sociedade colonial, sobretudo no que respeita à sua administração e economia, com base em Palacín (1978) e Salles (1992), de modo a corroborar a premissa de que léxico e cultura estão intimamente associados.

Além disso, apresentaremos definições para as espécies documentais mencionadas no texto, com foco nas suas finalidades no período colonial e no texto analisado, tendo como suporte teórico Belloto (2002). Finalmente, teceremos considerações sobre o gênero epistolar como fonte dos estudos históricos da língua, atentando-nos para a sua estrutura discursiva (Berlinck; Barbosa; Marine, 2008). De outra parte, objetiva-se demonstrar a instabilidade grafemática observada no documento, tendo em vista que a língua sofre modificações sob a ação do tempo e do uso que dela fazem os falantes.

\section{Aspectos estruturais da carta e reflexões sobre o seu conteúdo}

O documento selecionado para análise é de natureza oficial e não-literária e pertence ao códice intitulado "Livro para servir no registro do caminho novo de Parati - Thomé Ignácio da Costa Mascarenhas (1724-1762)”. Localiza-se no fólio sessenta e oito, do recto ao verso, contém a indicação do local do registro, a saber, a Capitania de Vila Boa de Goiás, e a assinatura do seu governador, Dom Marcos de Noronha, o Conde dos Arcos.

Sobre a configuração estrutural da carta, convém notar que ela apresenta a numeração 7 no centro da margem superior do fólio, que se repete na linha abaixo, à margem esquerda. Possui setenta e uma linhas de extensão e se inicia com o pronome de tratamento Senhor, a indicar que o destinatário da carta era Sua Majestade. Tal forma de tratamento representava a submissão do remetente ao Soberano, i. é, ao rei D. José I, como observa Acioli (1994). Por sua vez, funcionários de cargos inferiores, como secretários de estado, governadores etc. eram referidos nas cartas analisadas através da expressão de tratamento Vossa Excelência. Isso demonstra o reconhecimento da hierarquia social existente entre os funcionários da administração colonial.

Como é recorrente em outros documentos que compõem o códice, a fórmula "He VossaMagestade Servido ordenarmepelaProvizaó inclusa" principia o documento e o enunciado "VossaMagestade mandará o quefor servido" 
o encerra. Ao final do mesmo, constaram, ainda, as datas tópica, ou seja, Vila Boa, e cronológica, a saber, 3 de janeiro de 1752, seguidas pela assinatura do governador da Capitania goiana. Consta a seguir a edição semidiplomática e justificada do documento acima referido:

| 68r. || <7> | <7> Senhor: He VossaMagestade Servido ordenarmepelaProvizaó inclusa | que informe com o meuparecer ouvindo ao Ouvidor geral sobre o reque | rimento que na Real presença deVossaMagestade poseraõ os moradores des- | taVilla eSeu destrito, emque expoem a vexaçaó comque aCamera | os obriga aterem balancas, e medidas aferidas deSeis emS[ei]s | meses, eSepor alguma omissaõ as naõ affêrem, ou naõ resistaõ | os Bilhetes pelo Escrivaó da mesmaCamera, Saõ conde | nádos em nove mil reiz, ficando Sempre obrigados aafferirem | os pesos ebalanças e aresistarem os bilhetes, e que o mesmo lhe | Sucede Se Senaó apresentaõ no acto daCorreyçaó adonde | fica cadahum condenádo em dés mil, e outo centos eSettenta | eSinco reis, e mais nascustas dos Officiáes, eque vallendoce de | huma Provizam deVossaMagestade de 10 deIunho de 1738 para | se Livrarem destas oppreçoens, selhe naó dera a ella oseu verda | deiro cumprimento. | Pela certidaó do Escrivam daCamera | que vay afolha___ Se verifica oser verdadeira arepresentaçaõ que | fizeraõ aVossaMagestade estes moradores, porque da mesma certidaõ | Consta que os officiaes daCamera obrigaõ aque tenhaó balan | ças, eas affiraõ, naó Só aos que vendem em Loges e tavernas, e aos | Rosseyros, e Lavradores que costumaõ vender os Seusfrutos, mas | tambem aos Alfayátes, eSapateyros, eatodos os mais officiaes | que usaõ de officios mecanicos, Sendo todos constrangidos aafferirem | os pezos, e balanças no mes deIaneyro, eafazerem revista dos | mesmos pesos ebalanças no mes deIulho, e tendo qualquer destes | homens alguma omissaõ; ou descuido emSatisfaser nestaparte | aos Editaes, eposturas daCamera, Saõ condenados de duas athé | Seis outávas de ouro aarbitrio dos mesmos officiáes daCamera. | Hé igualmente certo que no acto daCorreyçaó que | todos os annos fasem os ouvidores, ficaõ tambem condenádos emSete | outavas ehum quarto de ouro, aLem das custas dos officiaes, Se | naó apresentaó as Licenças tiradas no tempo mencionado pelos edi- | taes da Camera. | NaConformidade do que VossaMagestade de | termina, mandey ouvir ao Ouvidor geral sobre este requerimento | e ||68v.|| [[e]] daSua informaçaõ que vay afolha__ consta aSua resposta, que | Supposto aqueyrafundamentar na dispoziçaõ da Ley do Reyno, naõ me | pare- 
cemproprias as intrepetacoens que lhe quer dár, porque o contrario | do que elle dis nasua informaçaõ, Se tem rezolvido por acordaons | daRellaçaó destaCorte, adonde os officiaes deofficios meca | nicos, Saõ izentos deSemelhantes impoziçoens, eaindaaquellas | pessoas que naforma daLey, saõ obrigadas aafferirem pezos, e ba | lanças, eatirarem Licenças dosenádo, naõ o fasendo por omis- | saõ ou descuido, nunca acondenaçaó chega ataó exorbitante | quantia como ade nove mil reis. Naõ obsta que nasua | informaçaõ diga oOuvidor, que esta pena hé adquada aSer | este Pais deMinnas, porque aexperiencia mostra claramente que | semelhantesCondenaçoens, ordinariamente cáhem sobre pessoas | pobres, enaõ vivem estas taõ abundantemente, que lhe naõ seja | muito penoso opagarem-nas taõ excessivas. | Os moradores das Minnas geraez padeciaõ estas mesmas extru | çoens, feytas pelas Cameras, e pelos Ouvidores; expozeraõ aVossaMagestade | a vexaçaõ emque viviaõ, e houve VossaMagestade por bem ordenar por Provi | zaõ de dés deIunho de 1738 deque remetto aCopia | afolha__ quepara se evitar o gravame quepadeciaõ, naõfossem obrigados | aafferir pesos emedidas, outras algumas pessoas alemdas decla | rádas naOrdenaçaõ doReyno, havendo por desterrado todo o a | buso emcontrario. Desta mesmaProvizaó Se quiseraõ valer | estes moradores, eSendo Ouvidos osOfficiaes daCamera, e Corre | gedor dacomarca sobre o requerimento, foraõ deparecer que | deviaõ usar dos meyos ordinarios, porque aProvizaõ por ser passáda | para diverso governo, naõ destróe aposse em que se achava a mesma | Camera. Pareceme que aSupplica quefasem estes morado- | res hé justa, e queSelhe deve conceder amesmagraça que | seConcedeo aos moradores dasMinnas geraez, determinandoce | aos Officiaes daCamera destaVilla que pelas afferiçoens das | balanças, e medidas, e pelos bilhetes que passa oEscrivaõ da | camera, naõ deyxem Levar mayor selario, do que se costuma | Levar nas Minnas geraez. VossaMagestade mandará o quefor servido. Villa | Boa 3 de Ianeyro de1752

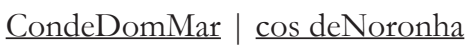

A edição do documento baseou-se nas "Normas para Transcrição de Documentos Manuscritos para a História do Português do Brasil”, disponíveis em Megale e Toledo Neto (2005), tendo em vista que é nosso objetivo compor uma fonte confiável e de fácil acesso para outros estudiosos. Em poucas palavras, trata-se de uma edição semidiplomática, que mantém a grafia das palavras, sua acentuação, as fronteiras de palavras, a pontuação e o uso de maiúsculas e minúsculas dos originais. 
A mudança de linha foi indicada por uma barra vertical, enquanto a mudança de fólio ou de sua face foi marcada por duas barras verticais, com a menção do número do fólio e de sua face, a saber, recto ou verso, de forma abreviada. Os trechos em itálico representam as letras que foram omitidas nas abreviaturas. A assinatura foi sublinhada e assinalou-se espaço intervalar maior deixado pelo escriba. As suposições do editor em casos de rasura ou corrosão foram colocadas entre colchetes simples, os trechos repetidos pelo escriba foram transcritos entre colchetes duplos e as inserções nas margens do documento foram inseridas entre os sinais $<>$.

Percebe-se que a carta é uma resposta do então governador da Capitania de Vila Boa, Conde Dom Marcos de Noronha, à ordem proveniente de D. José I para que desse seu parecer sobre a representação dos moradores acerca da cobrança abusiva de impostos sobre as atividades comerciais. Com isso, evidencia-se que caberia ao Soberano a determinação final sobre o requerimento feito pelos moradores.

Inicialmente, o governador expõe a ordem recebida de Sua Majestade e dá detalhes sobre o requerimento dos moradores. Em seguida, ele relata o seu procedimento diante de tal solicitação, qual seja, ouvir o ouvidor geral a respeito da queixa supracitada. Feito isso, o governador explicitou o seu parecer, justificando-o minuciosamente.

A carta aponta para um aspecto proeminente da economia colonial, vale dizer, a arrecadação tributária, que a essa época já se revelava onerosa à população, tanto que esta encaminhou uma representação à Corte sobre as cobranças excessivas de impostos, que causavam graves prejuízos aos comerciantes em geral.

Conforme determinação da Câmara, os comerciantes precisavam possuir balanças para realizar a aferição das medidas a cada seis meses e, então, registrar seus bilhetes. Bilhetes estes que correspondiam a títulos de obrigação, segundo Ferreira (2004), e que deveriam ser apresentados na correição, que é definida por Bluteau (1712-1728: 563) como a

Expedição, em que vay o Corregedor com seus officiaes pela comarca tomar conta de todos os maleficios, que nella se comettem, assi por devassa, como por vistas, \& revistas de papeis, \& livros, \& tudo o mais 
deyxando capitulos, do modo com que se há de proceder dalli em diante em algumas materias.

Caso não procedessem dessa maneira, os comerciantes ficavam obrigados a pagar uma multa de mais de dez mil réis. Portanto, em tais visitas, feitas pelo corregedor ou pelo ouvidor da comarca, estavam entre as atribuições destes profissionais registrar as reclamações da população, propondo-lhes soluções, e investigar os delitos cometidos, dentre eles as pendências de alguns profissionais no tangente às suas obrigações tributárias.

A carta em análise menciona que não apenas os comerciantes de lojas e tabernas estavam sujeitos ao pagamento do imposto referido, mas também os roceiros, lavradores, alfaiates e sapateiros. A esse respeito, vale destacar que as profissões de lavrador r roceiro não se confundem no documento, pelo contrário, são tratadas como categorias profissionais distintas.

Perscrutando as definições de ambas as lexias em dicionários próximos à época em que a carta foi escrita, vale dizer, Bluteau (1712-1728) e Moraes Silva (1813), à luz do seu emprego no documento, obtivemos as seguintes acepções:

\begin{tabular}{|l|l|}
\hline \multicolumn{1}{|c|}{ Lexias } & \multicolumn{1}{c|}{ Acepções } \\
\hline lavrador & $\begin{array}{l}\text { "Aquelle que cultiva terras proprias, ou alheyas. (...) fertiliza a terra, } \\
\text { \& propaga o gado" (Bluteau, 1712-1728: 55). }\end{array}$ \\
\hline roceiro & $\begin{array}{l}\text { "O que faz, e planta roçados, commummente de mandioca, e legu- } \\
\text { mes" (Moraes Silva, 1813: 636). }\end{array}$ \\
\hline
\end{tabular}

Quadro 1: Cotejo das acepções das lexias lavrador e roceiro.

Desse modo, verifica-se que os ramos profissionais supracitados têm em comum a fertilização e o cultivo da terra. Entretanto, o lavrador, para além disso, desempenha tarefas relacionadas à criação de gado, nos dizeres de Bluteau (1712-1728). Outro ponto distintivo entre tais atividades, de acordo com Moraes Silva (1813), é que o roceiro, geralmente, cultivava roçados de mandioca e legumes, de modo que esta profissão consistia em uma ramificação do ofício de lavrador ou de agricultor. É o que corrobora a acepção de roceiro em Ferreira (2004) como "Pequeno lavrador". Ademais, Moraes Silva (1813) 
aponta outra distinção entre tais lexias ao definir lavrador como o profissional que cultiva a terra sem se valer de ofícios mecânicos.

Para Salles (1992), no início da mineração em Goiás, não havia preocupação com a agricultura. No entanto, esse quadro sofreu uma mudança significativa devido à crise alimentar desencadeada pelo crescimento populacional. A partir de então, a agricultura passou a coexistir com a mineração. Segundo a autora (1992: 63), "Formaram-se os sítios de lavouras nas imediações dos povoados, sede dos mineiros e de sua escravaria".

Quanto à lexia alfaiate, convém assinalar que, na atualidade, tal profissão revela-se elitizada. Assim é que parece ser bastante provável que a clientela do alfaiate, no contexto histórico em que o documento foi redigido, era formada em geral por pessoas ligadas ao aparelho administrativo, do mais alto escalão da sociedade goiana no período colonial, já que os demais moradores detinham um poder de compra mais restrito.

Faz-se necessário, ainda, elucidar em que consistiam os estabelecimentos comerciais citados, a saber, loja e taberna, apontando as similaridades e divergências entre elas. Para Moraes Silva (1813: 758), taberna é a "Casa onde se vende por miudo o vinho, azeite, e alguma coisa de comer". Nos dias atuais, tal vocábulo está relacionado, de modo geral, aos ambientes noturnos e à promiscuidade, semelhante aos bares da atualidade. O verbete loja, por sua vez, possui um sentido mais amplo e geral, uma vez que Bluteau (1712-1728: 175) o define como "A officina, em que se vende qualquer mercancia. (...) Casa terrea, que não he nobre", acepções estas que permanecem inalteradas na atualidade.

Depreende-se, ainda, pelas acepções expostas acima, que a principal distinção entre os locais referidos é que a taberna é um tipo de loja destinada essencialmente ao consumo de bebidas, enquanto a lexia loja é usada para designar as dependências que comercializam as mais diversas mercadorias.

Pelo quadro delineado até aqui, nota-se que a Capitania goiana era formada por pequenos comércios, por atividades mecânicas e por uma modesta agricultura. As propriedades rurais localizavam-se no seu entorno, o que se preservou ainda na atualidade, visto que os pequenos sítios e fazendas goianas encontram-se nas imediações dos seus centros urbanos. Percebe-se, desse modo, a tênue fronteira entre o campo e a cidade ou, em outras palavras, entre o rural e o urbano, que configura o estado de Goiás ainda hoje, sobretudo no que concerne às cidades mais interioranas, matizadas pela vivência rural. 
São dignas de nota as unidades monetárias referidas no documento, quais sejam, réis e oitavas, sendo que a primeira era a moeda em uso no Brasil e em Portugal na época e a segunda aponta para o fato de o ouro ter sido usado com frequência no comércio, em razão da falta de moedas. Salles (1992: 120) destaca que "durante as primeiras décadas da colônia, o padrão de troca era a oitava de ouro, mas a documentação ora apresenta o valor dos preços em oitavas de ouro, ora em cruzados ou mil réis". Segundo Palacín (1978), as pessoas de origem humilde não conheciam o valor das coisas em réis, mas em oitavas de ouro, vinténs ou patacas.

É interessante observar a designação de vila à Capitania goiana, em consonância com a sua extensão populacional. Com base na definição deste item lexical em Bluteau (1712-1728), isso significa que, embora Vila Boa não pudesse ser considerada uma cidade pelo seu contingente populacional, ela tinha o status de vila, por ser maior que uma aldeia ou um arraial e já contar com uma estrutura jurídica e administrativa básica, uma vez que possuía uma Câmara e um juiz.

O documento menciona alguns funcionários do Governo que participavam da administração da Capitania, tais como o ouvidor, o escrivão e o corregedor, sendo que a lexia corregedor foi empregada como sinônimo de ouvidor. Tal similaridade pode ser corroborada pelas acepções dos verbetes corregedor e ouvidor em Ferreira (2004), haja vista que o primeiro foi definido como "Antigo magistrado cujas atribuições eram análogas às dos atuais juízes de direito" e o segundo como "Antigo magistrado com as funções do atual juiz de direito". Assim, o ouvidor ou o corregedor era o oficial do governo responsável pela correição e pela fiscalização da arrecadação de impostos. Era, ainda, um ministro de alçada criminal, cível e econômica. O escrivão, por sua vez, era aquele que realizava registros de atos públicos.

À esteira de Salles (1992), as rendas da Capitania eram incumbências da Fazenda Real, arrecadando impostos como as entradas, os dízimos e as passagens, juntamente com a Câmara do senado, responsável por impostos utilizados em benfeitorias nos arraiais, e com o Real Erário, ao qual cabia a cobrança dos quintos, dos tributos de ofícios e de um por cento dos contratos. 


\subsection{Notas sobre as espécies documentais referidas na carta em estudo}

Merece registro que diversas espécies documentais foram referidas no documento, razão pela qual este estudo se confina com a Diplomática, cujo objeto de estudo, nas palavras de Belloto (2002), é a estrutura formal do documento, ou seja, a construção do discurso de acordo com determinados fins. Nesse sentido, cumpre esclarecer as propriedades mais elementares de cada espécie documental mencionada no texto, mediante a descrição da sua natureza e finalidade, sumarizadas no quadro a seguir:

\begin{tabular}{|l|l|}
\hline \multicolumn{1}{|c|}{$\begin{array}{c}\text { Espécie } \\
\text { documental }\end{array}$} & \multicolumn{1}{c|}{ Definição em Belloto (2002) } \\
\hline Acórdão & "Decisão proferida em grau de recurso por tribunal" (p. 46). \\
\hline Certidão & $\begin{array}{l}\text { "Documento emanado de funcionário de fé pública, mediante } \\
\text { o qual se transcreve algo já registrado em documento de assen- } \\
\text { tamento, elaborado segundo as normas notariais ou jurídico- } \\
\text {-administrativas" (p. 57). }\end{array}$ \\
\hline Edital & $\begin{array}{l}\text { "Aviso publicado a mando de autoridade competente em órgão } \\
\text { de imprensa ou afixado em lugar público" (p. 66). }\end{array}$ \\
\hline Informação & $\begin{array}{l}\text { "Ato judicial que, no processo, contém os depoimentos das } \\
\text { testemunhas" (p. 69). }\end{array}$ \\
\hline Lei & $\begin{array}{l}\text { "preceito real que obriga os súditos a obedecerem as ordens" } \\
\text { (p. 71). }\end{array}$ \\
\hline Ordenações & $\begin{array}{l}\text { "codificação das leis em vigor que se fizeram em Portugal, nos } \\
\text { reinados de D. Afonso V" (p. 77). }\end{array}$ \\
\hline Parecer & $\begin{array}{l}\text { "opinião técnica ou científica sobre um ato, servindo de base } \\
\text { para a tomada de decisão" (p. 78). }\end{array}$ \\
\hline Postura & $\begin{array}{l}\text { "Deliberação municipal escrita que obriga a população ao } \\
\text { cumprimento de certos deveres de ordem pública" (p. 80). }\end{array}$ \\
\hline Provisão & $\begin{array}{l}\text { "ato pelo qual o rei confere algum benefício ou cargo a alguém } \\
\text { ou emite ordem baseada em dispositivos anteriores" (p. 82). }\end{array}$ \\
\hline Representação & $\begin{array}{l}\text { "Correspondência assinada por grupo de pessoas ou por órgão } \\
\text { colegiado expondo ou solicitando algo a uma autoridade" (p. } \\
\text { 86). }\end{array}$ \\
\hline
\end{tabular}




\begin{tabular}{|l|l|}
\hline Requerimento & $\begin{array}{l}\text { "Instrumento que serve para solicitar algo a uma autoridade } \\
\text { pública e que, ao contrário da petição, está baseado em atos le- } \\
\text { gais ou em jurisprudência" (p. 86). }\end{array}$ \\
\hline Resolução & $\begin{array}{l}\text { "Ato emanado de órgão colegiado registrando uma decisão ou } \\
\text { uma ordem no âmbito de sua área de trabalho" (p. 87). }\end{array}$ \\
\hline
\end{tabular}

Quadro 2: Síntese das definições de algumas espécies documentais em Belloto (2002).

As definições transcritas acima foram extraídas da obra Como fazer análise diplomática e análise tipológica de documento de arquivo, de Heloísa Liberalli Belloto (2002), de maneira resumida, a fim de equacionar dúvidas acerca da finalidade de tais espécies documentais no período colonial. Além disso, é relevante pontuar sobre o papel de cada gênero textual tomado individualmente no corpo do texto, o qual se vincula a uma atividade desempenhada no seio da administração colonial brasileira.

De acordo com Belloto (2002: 17), o documento diplomático compõe-se do "registro legitimado do ato administrativo ou jurídico", sendo que o primeiro consiste em uma manifestação da vontade da administração pública e o segundo visa à defesa dos direitos públicos e privados. Assim sendo, todo documento representa uma atividade, que influencia diretamente a forma do seu registro. Este registro, por sua vez, precisa apresentar uma dada configuração para ter validade jurídica e é esta configuração da forma do documento que determina a espécie documental.

No documento analisado, a provisão insurgiu como o instrumento que transmitiu uma ordem real ao governador da Capitania de Vila Boa de Goiás, como bem sugere a sua definição no Quadro 2. Nesta, um parecer sobre o requerimento feito pelos moradores acerca da cobrança de impostos pela Câmara foi solicitado ao dito governador, a indicar que a decisão de Sua Majestade se basearia na opinião dada por este.

Quanto ao referido requerimento, cabe afirmar que se tratou de uma solicitação feita pelos moradores ao Soberano para que a provisão real destinada à população de Minas Gerais e datada de 10 de junho de 1738 também fosse cumprida no território goiano, minorando os abusos até então vivenciados por seus moradores. Tal provisão serviu, portanto, de base jurídica ao requerimento, tendo sido enviada em anexo à carta escrita pelo governador a D. José I. 
Já a certidão do escrivão da Câmara seguiu também anexada à carta, uma vez que comprovava o que era descrito pelos moradores na representação por eles apresentada à Sua Majestade, contendo a sua queixa. Tal representação expunha à Corte as vexações pelas quais passavam os comerciantes goianos devido ao pagamento de taxas de impostos abusivas ao governo.

Por outro lado, as posturas da Câmara postulavam as determinações do Governo ao povo, enquanto os editais destinavam-se a divulgar tais prescrições em lugares públicos, de fácil acesso à população em geral. O não cumprimento das posturas e editais, no entanto, implicava a imputação de multas altíssimas aos comerciantes. Ademais, a informação, no documento em estudo, compôs-se do depoimento colhido do ouvidor a respeito da queixa feita pelos moradores e também foi enviada em anexo à Coroa Portuguesa.

No que tange à licença, que não foi definida por Belloto (2002), é válido asseverar que consiste em um documento que autorizava o exercício de uma atividade profissional por um período de tempo e deveria ser apresentada ao ouvidor durante a correição, sob pena de multa. Sem ela, o desempenho de uma profissão ficava ilegal. Segundo Ferreira (2004), a licença pode ser definida como a "Permissão outorgada pela autoridade competente para o estabelecimento de uma indústria ou comércio ou para o exercício de uma atividade, em geral mediante o pagamento de uma taxa" ou ainda como o "Documento que atesta a concessão de uma licença”.

A Lei do Reino, por seu turno, continha os preceitos reais e havia sido usada pelo ouvidor para fundamentar a sua posição diante da queixa dos moradores. Contudo, o governador preconizava que a mesma era refutada por um acórdão proveniente da Relação da Corte, que decidia o oposto previsto pela lei. Para embasar mais uma vez o seu parecer, o governador se vale das disposições das Ordenações do Reino, que acabaram prevalecendo na querela sobre o mesmo tema em Minas Gerais. Estas se assemelhavam à Constituição Nacional da atualidade e por isso tinham supremacia na questão.

Em suma, as espécies documentais mencionadas no documento evidenciam os trâmites administrativos e jurídicos decorrentes de uma representação feita pelos moradores à Sua Majestade. Ademais, demonstram a atuação do governador da capitania e da Corte na questão, conforme as suas posições 
hierárquicas. Como vimos, o governador submeteu vários documentos à apreciação de Sua Majestade para que ela pudesse tomar sua decisão final.

No intuito de fundamentar o seu parecer, ele se utilizou da certidão feita pelo escrivão da Câmara, a qual descrevia os termos da cobrança de impostos no comércio, e do acórdãos da Relação da Corte, que, a seu ver, era soberano à Lei do Reino e contrariava a interpretação dada pelo Ouvidor geral a esta, a qual constava da informação colhida pelo governador. Com base no dito acórdãos, o governador considerava infundados os argumentos do ouvidor contra a queixa dos moradores e inapropriada a sua interpretação da Lei do Reino.

Além disso, o governador se utiliza de uma provisão de Sua Majestade do ano de 1738 destinada ao governo de Minas Gerais, favorável aos interesses da população, vale dizer, atendendo aos seus apelos, com vistas a reforçar a sua opinião favorável à representação dos moradores. Ele ainda menciona que a Ordenação do Reino embasou tal provisão, legitimando o seu conteúdo.

Assim é que as espécies documentais fundamentam o parecer do governador e são estratégias usadas para persuadir a Coroa Portuguesa da legitimidade das suas conclusões. Espécies documentais, como a provisão, o edital, a postura, a lei e a ordenação, de outra parte, destinavam-se a veicular informações ou ordens reais.

\subsection{A carta oficial nos estudos históricos da língua}

De acordo com Berlinck, Barbosa e Marine (2008: 172), a carta “além de servir como meio de comunicação entre pessoas distantes, registra as memórias e as condições de vida (aspectos sociais) de uma época, servindo como fonte de estudos lingüísticos, sócio-históricos etc.”. Desse modo, a carta contém, de modo geral, informações sobre o modo de interação entre duas entidades, o qual fica evidente nas formas de tratamento empregadas e no uso de um maior ou menor grau de formalidade. A isto podemos acrescentar os aspectos linguísticos que se manifestam na carta, fazendo um registro importante do estado da língua em uso na época.

É válido asseverar que os documentos oficiais dão mostras do funcionamento de uma dada instituição. No caso da carta oficial elencada para a presente investigação, pode-se notar que ela evidencia aspectos da administração colonial 
no Brasil e, mais especificamente, das relações entre a Corte e o governo da Capitania de Vila Boa de Goiás e, particularmente, de suas vias de comunicação.

As cartas possuem um caráter interativo, ficando marcadas as presenças do destinatário, que no documento em análise é o rei D. José I, e do remetente, isto é, o governador de Vila Boa, Dom Marcos de Noronha, conforme consta ao final do mesmo. O discurso da carta é estruturado conforme a posição hierárquica do remetente em relação ao destinatário, o que se percebe nos pronomes e expressões de tratamento, tais como "Senhor" e "VossaMagestade", assim como no fragmento "Real presença". Para as autoras referidas acima (2008: 175), estes "exprimem o grau de distanciamento e a subordinação em que uma pessoa voluntariamente se põe em relação a outra".

Por esse prisma, nota-se que o governador se coloca em uma posição de subordinado em relação ao Soberano, demarcando sua posição hierárquica inferior em relação a este. Em decorrência disso, é esperada uma escrita mais formal do texto, inclusive com um tom de solenidade, reafirmando a submissão do governador ao rei, como corrobora o trecho "NaConformid ade do que VossaMagestade de | termina". Percebe-se, ainda, que não há tratamentos do tipo nominal no texto, sendo que o remetente refere-se ao rei pelas expressões de tratamento já mencionadas e ao ouvidor geral pelo seu cargo.

\section{A Variação grafemática no documento: ecos da escrita colonial bra- sileira}

Passando agora à discussão da variação grafemática observada no documento, concordamos com Faraco (2005: 24) que diz que "a língua é uma realidade heterogênea, multifacetada e que as mudanças emergem dessa heterogeneidade". Depreende-se desta assertiva que a língua não permanece inalterável ao longo do tempo, pelo contrário, precisa mudar para atender às necessidades sócio-interativas dos falantes. Essa mudança se dá nos mais diversos níveis da língua, a saber, ortográfico, fonético-fonológico, sintático, lexical, morfológico, discursivo etc. Dessa forma, pode-se dizer que a variação é inerente à língua e cada sincronia revela um estado de língua notadamente diverso.

Destacam-se os seguintes casos de variação grafemática no documento analisado: a) uso do $<\mathrm{g}>$ por $<\mathrm{j}>$ (Magestade, logas); b) uso do $<$ h $>$ em contex- 
tos diferentes dos atuais (Hé, cáhem, huma); c) uso indiscriminado dos grafemas $<_{\mathrm{s}}>,<_{\mathrm{z}}>$ e $<_{\mathrm{c}}>$ para os fonemas /z/ e /s/ (Provizaó, reiz, dispoziçaõ, dis, izentos, Sinco, Rosseyros, pezos, rezolvido, impoziçoens, geraez, dés, fasem); d) verbos com a terminação <ão > em vez de <am> (aprezentaõ, obrigaõ, tenhaó, affiraõ, costumaõ, usaõ, ficaõ, padeciaõ, expozeraõ, viviaõ, padeciaõ, foraõ, deviaõ); e) consoantes geminadas: Settenta, vallendo, oppreçoens, ella, afferirem, annos, Supposto, Rellaçaó, officios, officiáes, Minnas, remetto, Supplica; f) rebaixamento das vogais $\left\langle\mathrm{u}>\right.$ em $<_{\mathrm{O}}>$ e $<\mathrm{i}>$ em $\langle\mathrm{e}>$ nas posições pré e pós-tônica (destrito, Officiáes, Editaes, expozeraõ, destróe, Concedeo); g) uso do $<y>$ por $<\mathrm{i}>$ (Correyçaó, vay, Rosseyros, Alfayátes, Sapateyros, mandey, queyra, Ley, Reyno, feytas, meyos, deyxem, mayor); h) nasalização das partículas $<$ õe $>$ e $<$ ão $>$ através do grafema $<$ n $>$ (oppreçoens, acordaons, Condenaçoens, afferiçoens, intrepetacoens); i) uso do $<\mathrm{i}>$ por $<\mathrm{j}>$ (Iunho, Ianeyro, Iulho); j) metátese da sílaba $<$ ter $>$ e síncope do $<\mathrm{r}>$ no grupo consonantal $<$ pr $>$ (intrepetacoens); k) síncope do $<\mathrm{r}>$ no grupo consonantal $<$ tr $>$ e uso do $<$ s $>$ por $<$ g $>$ (resistaõ, Resistarem); l) uso do ditongo $<$ ou $>$ por $<$ oi $>$ (outo, outávas); m) uso de <am> em lugar de <ão $>$ (Provizam, Escrivam).

Levando-se em consideração que o documento em análise data do século XVIII, não causa estranheza ao pesquisador habituado ao estudo histórico da língua que a escrita apresente profundas divergências em relação à norma ortográfica estabelecida como padrão nos dias atuais. É interessante notar, contudo, que muitas destas variações grafemáticas vêm à tona na escrita de pessoas com baixo índice de escolaridade, motivadas com frequência pela influência da oralidade e/ou pela arbitrariedade que rege a norma ortográfica em voga nos dias de hoje, a qual geralmente tem como base os padrões do português europeu.

Além disso, não se pode esquecer que não havia uma normatização rígida para a grafia a esta época e, face a isto, os escribas precisavam elaborar hipóteses para a escrita das palavras, o que resultava na instabilidade grafemática observada em muitos documentos desse período. Diante disso, era comum que um mesmo escriba realizasse registros grafemáticos distintos de uma palavra em um único documento. É o que podemos perceber nos seguintes vocábulos compilados da carta em estudo: Provizam/Provizao, Escrivam/ Escrivaõ, pesos/pezos. 
Desta feita, "cada estado de língua, definível no presente ou em qualquer ponto do passado, é sempre resultado de um longo e contínuo processo histórico" (Faraco, 2005: 45), porquanto o modo como a língua se apresenta em um dado estágio do seu desenvolvimento é afetado pelo contexto histórico-social em que ela se manifesta. Em virtude disso, parece evidente a influência do período pseudo-etimológico da escrita em alguns exemplos extraídos da carta, pois ele preconiza um retorno aos clássicos gregos e latinos, com o uso do $<y>$ no lugar do $<\mathrm{i}>$ e, sobretudo, no uso das consoantes geminadas, sendo uma tendência comum na escrita da época a preferência pelo supérfluo. Vale lembrar, no entanto, que a língua como objeto histórico não muda no mesmo ritmo acelerado que a sociedade, ou seja, suas mudanças são gradativas, ocorrem lentamente no decurso do tempo e são parciais, não atingem a totalidade do sistema linguístico.

Depreende-se, assim, que apesar de ser uma carta oficial, este documento dá indícios da variedade vernacular da língua no século XVIII e podemos observar nele alguns contornos da variação grafemática no período colonial. De modo geral, a escrita tende a ser mais formal que a fala. Contudo, Berlinck, Barbosa e Marine asseveram que

embora a escrita normalmente seja considerada uma manifestação da linguagem mais formal, que utiliza recursos que obedecem mais estritamente às normas ditadas pela gramática tradicional, é importante salientar que, de fato e com freqüência, ela se utiliza de recursos associados à linguagem oral (2008: 180).

Por conseguinte, apesar de ser um documento escrito de caráter oficial e permeado de formalidades, é possível entrever na grafia do escriba da presente carta que as suas hipóteses sobre a escrita de algumas palavras são norteadas pela pronúncia das mesmas. É nesse contexto que Mattos e Silva (2008: 21) preconiza o uso da fonte escrita para o estudo das variações linguísticas pelo viés diacrônico, afirmando que

Sendo a documentação escrita que permanece e sendo ela uma representação convencional da fala, teremos o reflexo da fala, que permite tirar conclusões, até certo ponto seguras, no nível morfofônico, já que, não havendo uma normatização ortográfica, a análise da variação da 
escrita oferece indícios para alguma percepção da voz, ou seja, da língua no seu uso primeiro.

Conclui-se, a partir dessa assertiva, que os historiadores da língua não podem se esquivar ao uso de fontes escritas para o estudo da língua usada em épocas muito remotas, uma vez que elas nos dão mostras do uso que se fazia da língua na modalidade oral naquele período e são, muitas vezes, a única forma de acessar a fala da época.

\section{Considerações finais}

Este estudo assentou-se na análise de uma carta oficial do século XVIII, levantando aspectos sócio-culturais, cuja explicação visou a favorecer a compreensão do texto editado. Assim, principiamos com a divulgação da edição semidiplomática do documento, cumprindo a função substantiva da Filologia, segundo Spina (1977) e, então, em um segundo momento, buscamos tecer considerações sobre a temática e a estrutura do texto, bem como sobre a sociedade e a cultura que nele se manifestam, efetuando assim a função transcendente, na denominação dada pelo referido autor. Assim sendo, resquícios da memória de fatos passados foram trazidos a lume e suas convergências e divergências com o quadro atual da região goiana foram, em geral, assinaladas.

Vale ressaltar que as definições de alguns vocábulos tiveram o intuito de facilitar a compreensão do que eles representavam no contexto sócio-cultural da época, em contraste com a sua dimensão significativa na atualidade. De igual maneira, a conceituação das espécies documentais objetivou elucidar a sua natureza e finalidade no período colonial, assim como a sua função no texto.

Intentamos, ainda, demonstrar a importância dos documentos oficiais antigos para os estudos históricos da língua, com destaque para a carta oficial, pois esta possui marcas da interação entre a Corte e o governo das Capitanias e da influência da posição hierárquica do remetente em relação ao destinatário na formalidade conferida ao texto. Ademais, as variantes gráficas encontradas no documento indicam a influência da oralidade e do período pseudo-etimológico na escrita da época, as quais são dignas de um estudo mais aprofundado. Isso reforça a hipótese de que, embora os documentos oficiais não reflitam o uso 
espontâneo da língua feito pelos escribas na época, eles abarcam indícios da variabilidade linguística presente na fala daquele período, haja vista a ausência de uma normatização ortográfica.

\section{Referências bibliográficas}

ARQUIVO HISTÓRICO ESTADUAL DE GOIÁS. Livro para servir no registro do caminho novo de Parati - Thomé Ignácio da Costa Mascarenhas (1724-1762). 1724-1762. fólios 66-139.

ACIOLI, V. L. C. (1994). A escrita no Brasil Colônia: um guia para leitura de documentos manuscritos. Recife: Editora Massangana; Fundação Joaquim Nabuco; Editora Universitária da Universidade Federal de Pernambuco.

BELLOTO, H. L. (2002). Como fazer análise diplomática e análise tipológica de documento de arquivo. vol. 8. Arquivo do Estado e Imprensa Oficial do Estado: São Paulo.

BERLINCK, R. A.; BARBOSA, J. B.; MARINE, T. C. (2008). Reflexões teórico-metodológicas sobre fontes para o estudo histórico da língua. Revista da ABRALIN, v. 7, n. 2, p. 169-195, jul./dez.

BLUTEAU, R. (1712-1728). Vocabulario portuguez \& latino. Coimbra: Collegio das Artes da Companhia de Jesus.

FARACO, C. A. (2005). Lingüística histórica: uma introdução ao estudo da história das línguas. vol. 12. ed. rev. amp. São Paulo: Parábola Editorial.

FERREIRA, A. B. H. (2004). Novo dicionário eletrônico Aurélio. 3. ed. Curitiba: Positivo.

MATTOS E SILVA, R. V. (2008). Caminhos da linguística histórica: ouvir o inaudível. São Paulo: Parábola Editorial.

MEGALE, H.; TOLEDO NETO, S. A. (2005) (Orgs.). Por minha letra e sinal: documentos do ouro do século XVII. Cotia, SP: Ateliê Editorial; FAPESP.

MORAES SILVA, A. (1813). Diccionario da lingua portugueza. 2. ed. Lisboa: Typographia Lacérdina.

PALACÍN, L. (1978). Goiás 1722-1822 - estrutura e conjuntura numa Capitania de Minas. 2. ed. Goiânia: Oriente.

SALLES, G. V. F. (1992). Economia e escravidão na capitania de Goiás. Goiânia: CEGRAF/ UFG.

SPINA, S. (1977). Introducão à edótica. São Paulo: Cultrix.

Recebido em: 02/01/2011

Aprovado em: 02/05/2011 